\title{
Effect of perinatal risk factors on neutrophil gelatinase-associated lipocalin (NGAL) level in umbilical and peripheral blood in neonates
}

\author{
AGNIESZKA KISIEL ${ }^{l}$, MARIA ROSZKOWSKA-BLAIM ${ }^{1}$, MAEGORZATA PAŃCZYK- \\ TOMASZEWSKA ${ }^{l}$, ANNA STELMASZCZYK-EMMEL ${ }^{2}$, ELŻBIETA GÓRSKA ${ }^{2}$, \\ MARIA BORSZEWSKA-KORNACKA \\ ${ }^{1}$ Department of Pediatrics and Nephrology, Medical University of Warsaw, Poland \\ ${ }^{2}$ Department of Laboratory Diagnostics and Clinical Immunology of Developmental Age, Medical University of Warsaw, Poland \\ ${ }^{3}$ Neonatal and Intensive Care Department, Medical University of Warsaw, Poland
}

\begin{abstract}
Introduction: Acute kidney injury biomarkers are opening a new era in diagnosing kidney failure. The requirement for a specific and sensitive marker of kidney function is highly desirable in neonates because the diagnostic possibilities in this age group are not sufficient. Recent research show that neutrophil gelatinase-associated lipocalin (NGAL) can have a great potential but there is a wide range of medical conditions, that may influence their expression.

The aim of the study was to evaluate the impact of perinatal risk factors on NGAL level in neonates.

Material and methods: NGAL was measured in umbilical cord blood and peripheral blood in full term neonates with perinatal risk factors during the first days of life.

Results: We found significantly higher umbilical cord blood NGAL levels in neonates with perinatal risk factors $(117.69 \mathrm{ng} / \mathrm{ml})$ compared to the control group $(64.37 \mathrm{ng} / \mathrm{ml})$. No significant difference in peripheral blood NGAL level was shown between the two groups. Umbilical cord blood NGAL level correlated positively with peripheral blood NGAL level $(r=0.36, p<0.01)$. Umbilical cord blood NGAL level was significantly higher in neonates with fetal distress and infection compared to neonates with other perinatal risk factors. Peripheral blood NGAL level was significantly higher in neonates with infection compared to neonates with other perinatal risk factors. Significantly higher umbilical cord blood $N G A L$ levels were seen in neonates born by operative delivery compared to born by natural delivery.
\end{abstract}

Key words: neonates, NGAL, AKI biomarkers.

(Cent Eur J Immunol 2017; 42 (3): 274-280)

\section{Introduction}

Neonates are the group that is most prone to acute kidney injury (AKI) $[1,2]$. Chronic maternal disease and pregnancy- or birth-related pathology may have a negative impact on neonatal renal function. Risk factors for AKI in neonates include prematurity, intrauterine hypoxia, and hypovolaemia, e.g. due to sepsis [1, 3, 4]. A harmful effect on the development and function of neonatal kidneys is also exerted by non-steroidal anti-inflammatory drugs (NSAIDs), angiotensin-converting enzyme inhibitors (ACEI), and aminoglycoside antibiotics used in pregnant women or in the neonatal period [5].

The rate of AKI in neonates is 6-24\% [2]. These figures are believed to be underestimated due to the (often) non-oliguric course of AKI and diagnostic challenges in this age group. Serum creatinine level remains the major diagnostic test for AKI, but it is a late marker of kidney damage [6]. Serum creatinine rises only two days after damage and/or with functional loss of $>50 \%$ of renal parenchyma. In addition, during the first 48-72 hours of neonatal life, it reflects maternal creatinine level $[7,8]$.

Despite significant improvement in perinatal care, mortality due to AKI remains high, in the range of $10-61 \%$ [2]. Outcomes of AKI mostly depend on rapid treatment initiation, preferably already during the preclinical stage. Preliminary studies indicate the usefulness of new early biomarkers of AKI such as neutrophil-gelatinase-associated lipocalin (NGAL), kidney injury molecule 1 (KIM-1), and interleukin 18 [9-11].

Because the most common pathogenetic factors in neonatal AKI are hypovolemia and hypoxia, NGAL is believed to be the most promising marker. Its expression

Correspondence: Agnieszka Kisiel, Department of Pediatrics and Nephrology, Medical University of Warsaw, Żwirki i Wigury 63 A, 02-091 Warsaw, Poland, e-mail: agnieszka.kisiel.med@gmail.com Submitted: 22.05.2017; Accepted: 16.08.2017 
increases in the thick part of the ascending limb of loop of Henle and the collecting ducts in response to toxic agents or ischaemia [12].

An increasing spectrum of clinical conditions that were identified as being associated with increased NGAL expression makes it necessary to consider potential factors that might affect the specificity of the measurements and interpretation of the results. Until now, elevated serum and urine NGAL was noted in neonates with intrauterine hypoxia [9, 13, 14], sepsis [15], and bronchopulmonary dysplasia [16] and after cardiac surgery using extracorporeal membrane oxygenation [17]. In a group of neonates with intrauterine hypoxia, Essajee et al. found that urinary NGAL was a predictor or mortality and hypoxic encephalopathy [18]. Several authors noted a negative correlation between urinary NGAL level and birth weight and gestational age [8, 19-21]. Although data concerning umbilical cord blood NGAL concentration are rare, they reveal a usefulness of NGAL measurements as a marker of intrauterine hypoxia [22].

Until now no widely accepted reference NGAL levels in neonates have been established. Serum and urine NGAL levels differed between studies by different authors [20, 23]. Most available data were obtained in preterm infants.

The aim of the study was to evaluate the effect of selected perinatal risk factors on umbilical cord and peripheral blood NGAL levels in neonates during the first days of life.

\section{Material and methods}

The research was approved by Ethical Committee of the Medical University of Warsaw. All the parents signed the informed consent before samples were obtained from neonates.

The study included full-term neonates (gestational age $\geq 37$ weeks) with potential perinatal risk factors (cases). The control group comprised 14 healthy full-term neonates.

Based on the available medical records, we analysed the course of pregnancy, taking into account maternal disease - hypertension, diabetes, infection during the last week of pregnancy, genital tract colonisation with Streptococcus agalactiae or Escherichia coli immediately before delivery, cholestasis of pregnancy, anaemia (haemoglobin level $<10 \mathrm{~g} / \mathrm{dl}$ ); medications used during pregnancy - antibiotics, NSAIDs, ACEI, steroid therapy; course of delivery - premature rupture of membranes $(\mathrm{PROM}) \geq 6$ hours (in accordance with local standards, women in labour are given antibiotic prophylaxis six hours after rupture of membranes), mode of delivery: spontaneous delivery or operative delivery (elective caesarean section, urgent caesarean section, vacuum-assisted delivery), foetal distress (as evidenced by decelerations in cardiotocography); neonatal condition after delivery - Apgar score at 1 and 5 minutes, birth weight, infection, congenital cardiac or renal disease, intrauterine hypoxia, and medications used.

In all neonates, NGAL level was measured in umbilical cord blood and peripheral blood serum obtained within five days of life (DOL 0-5). Serum was stored at $-80^{\circ} \mathrm{C}$ until assays. Measurements were made by the immunoenzymatic method using NGAL ELISA Kit 036 (BIO Porto ${ }^{\circledR}$ Diagnostics), and the results were expressed in $\mathrm{ng} / \mathrm{ml}$.

A suspected infection was an indication for C-reactive protein (CRP) level measurement and/or complete blood count evaluation. Umbilical blood gases were indicated in cases of suspected neonatal hypoxia and in operative delivery.

Neonatal infection was diagnosed based on elevated CRP level and/or leukocyte count. Intrauterine hypoxia was defined as the Apgar score $\leq 6$ at 1 minute and/or umbilical blood $\mathrm{pH} \leq 7.1$.

\section{Statistical analysis}

Statistical analysis was performed using Statistica 10 software (StatSoft). Normal distribution of the variables was tested using the Shapiro-Wilk test. Normally-distributed variables were expressed as mean values and standard deviation, and non-normally-distributed variables were expressed as median values and ranges. NGAL levels were log-transformed to obtain a normal distribution. Results were compared between groups using the Student t test, and relations between the evaluated variables were assessed using linear regression. $P<0.05$ was considered statistically significant.

\section{Results}

We studied 62 neonates (33 males and 29 females) with perinatal risk factors at a mean gestational age of 38.9 \pm 0.92 weeks, and 14 healthy neonates (nine males and five females) at a mean gestational age of $38.61 \pm 1.27$ weeks, who constituted the control group. Clinical characteristics and details regarding the mode of delivery are shown in Table 1.

We found no significant differences between the study and control groups with regard to gender distribution, gestational age, birth weight, and Apgar score at one and five minutes (Table 1).

In $11 \%$ of women in the study group and in one $(7 \%)$ woman in the control group the risk of premature delivery was diagnosed. All these women were treated using glucocorticosteroids.

Antibiotics (ampicillin, amoxicillin-clavulanate, or cefuroxime) due to $\mathrm{PROM} \geq 6$ hours, genital tract colonisation, or infection were used in 42 women. No women required treatment with NSAIDs or ACEI.

Antibiotic therapy with ampicillin and netilmicin was used due to intrauterine infection in seven neonates (11\%). 
Table 1. Clinical characteristics of neonates with potential risk factors for acute kidney injury (AKI)

\begin{tabular}{lccc}
\hline & $\begin{array}{c}\text { Cases } \\
(\boldsymbol{n}=\mathbf{6 2})\end{array}$ & $\begin{array}{c}\text { Controls } \\
(\boldsymbol{n}=\mathbf{1 4})\end{array}$ & $\boldsymbol{p}$ \\
\hline Gender, n (\%) & $33(53)$ & $9(64)$ & $\mathrm{NS}$ \\
$\begin{array}{l}\text { Male } \\
\text { Female }\end{array}$ & $29(47)$ & $5(36)$ & $\mathrm{NS}$ \\
\hline Gestational age (weeks) & $38.93 \pm 0.92$ & $38.61 \pm 1.27$ & $\mathrm{NS}$ \\
\hline Mode of delivery, $n(\%)$ & & & \\
Vaginal & $25(41)$ & $9(64)$ & $\mathrm{NS}$ \\
Operative** & $37(59)$ & $5(36)$ & $\mathrm{NS}$ \\
\hline Birth weight (g) & 3325.00 & 3312.74 & $\mathrm{NS}$ \\
& \pm 442.31 & \pm 488.95 & \\
\hline Apgar score* & & & \\
1-min & $10(5-10)$ & $10(8-10)$ & $\mathrm{NS}$ \\
5-min & $10(6-10)$ & $10(8-10)$ & NS \\
\hline *Median (range) & & &
\end{tabular}

*Median (range).

**Caesarean section and vacuum extractor

Table 2. Umbilical cord and peripheral blood NGAL levels (median, range) in full-term neonates with perinatal risk factors and the control group.

\begin{tabular}{cccc}
\hline & \multicolumn{2}{c}{ NGAL $(\mathbf{n g} / \mathbf{m l})$} & \multirow{2}{*}{$\boldsymbol{p}$} \\
\cline { 2 - 3 } & $\begin{array}{c}\text { Cases } \\
(\boldsymbol{n}=\mathbf{6 2})\end{array}$ & $\begin{array}{c}\text { Controls } \\
(\boldsymbol{n}=\mathbf{1 4})\end{array}$ & \\
\hline $\begin{array}{c}\text { Umbilical } \\
\text { cord blood } \\
\text { NGAL }\end{array}$ & $\begin{array}{c}117.69 \\
(17.47-536.57)\end{array}$ & $\begin{array}{c}64.37 \\
(30.36-142.04)\end{array}$ & $<0.01$ \\
\hline $\begin{array}{c}\text { Peripheral } \\
\text { blood NGAL }\end{array}$ & 179.11 & 155.28 & NS \\
\hline & $p<0.05$ & $(34.07-445.57)$ & \\
\hline
\end{tabular}

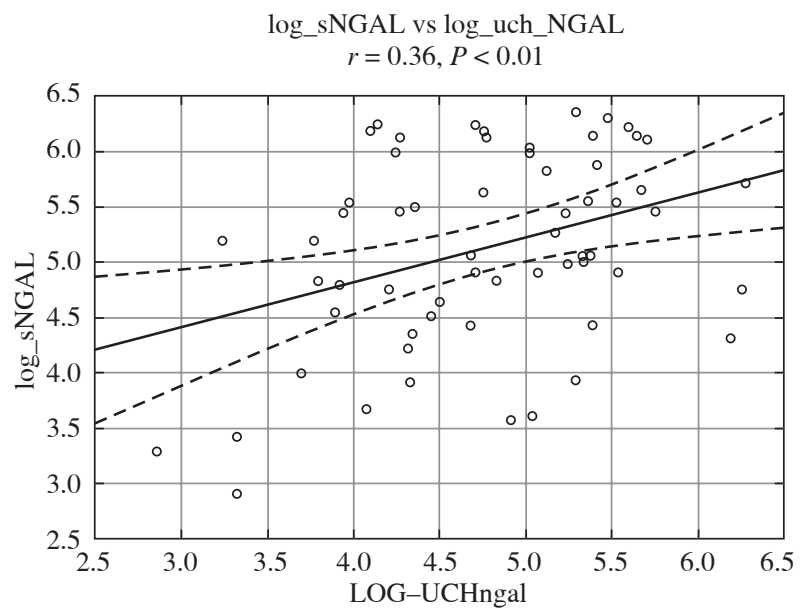

Fig. 1. Correlation between log-transformed umbilical cord NGAL (log_ucbNGAL) and peripheral blood NGAL (log_sNGAL) levels in neonates with perinatal risk factors
Potential risk factors for kidney injury were divided into three categories: maternal disease and pregnancy-related, perinatal, and neonatal. Chronic maternal disease or pregnancy-related pathology was found in 51 pregnant women (82\%), most commonly diabetes in 23 (37\%) and genital tract colonisation with Streptococcus agalactiae or Escherichia coli before the delivery in 22 (35\%). Infection was diagnosed in 20 pregnant women (32\%), including elevated CRP level (median $29 \mathrm{mg} / \mathrm{dl}$, range 12-190 mg/ $\mathrm{dl}$ ) in 17 , and leukocyte count $>16,000 / \mu \mathrm{l}$ in the remaining three in whom CRP level was not measured. Hypertension was diagnosed in seven mothers $(11 \%)$, anaemia with haemoglobin level $<10 \mathrm{~g} / \mathrm{dl}$ in three $(6 \%)$, and intrahepatic cholestasis of pregnancy in two $(3 \%)$.

Perinatal risk factors were noted in 41 neonates $(66 \%)$. PROM and foetal distress were found in 26 cases (42\%), and both these factors were present in 11 of these children.

Neonatal risk factors were present in 26 children (42\%): congenital defects in $17(27 \%)$, including cardiac in 11 neonates and urinary in six neonates; and infection in 10 neonates $(16 \%)$, with the diagnosis based on an elevated CRP level (mean $23.5 \pm 7.71 \mathrm{mg} / \mathrm{dl}$ ) with the mean leukocyte count of 20,300 $\pm 10,480 / \mu l$ in nine neonates, and based on isolated leucocytosis $(40,000 / \mu \mathrm{l})$ in one neonate; intrauterine hypoxia was found in four neonates, with the diagnosis based on low umbilical blood $\mathrm{pH}$ of 7.04-7.1 in three neonates; two neonates had low Apgar score at one minute (five and six points, respectively).

Overall, one to seven perinatal risk factors were present in individual neonates.

Umbilical cord and peripheral blood NGAL levels are summarised in Table 2. Both umbilical cord and peripheral blood NGAL level in neonates with perinatal risk factors was higher compared to the control group, although statistical significance was reached only for umbilical cord blood NGAL level $(p<0.01)$. Both in the study group and the control group, NGAL level was significantly higher in peripheral blood than in umbilical cord blood $(p<$ $0.05)$. The mean timing of peripheral blood collection in the study group and the control group was similar (1.78 \pm 0.93 and $1.49 \pm 0.83$ DOL, respectively). We found a significant positive correlation between log-transformed umbilical cord and peripheral blood NGAL levels $(\mathrm{r}=0.36$; $p<0.01$ ) (Fig. 1).

The effect of specific perinatal risk factors on umbilical cord and peripheral blood NGAL levels is shown in Table 3 and 4 . The highest umbilical cord blood NGAL levels were noted in neonates with infection and intrauterine hypoxia. Umbilical cord blood NGAL levels in neonates with perinatal risk factors related to pregnancy-related pathology and maternal disease (diabetes, maternal infection, genital tract colonisation, hypertension), perinatal pathology (PROM, foetal distress), and neonatal pathology (infection, congenital defects) were significantly higher ( $p<$ 0.05 ) compared to the control group. Due to low sample 
Table 3. Comparison of umbilical cord blood NGAL levels in neonates with a specific risk factor vs. neonates with other risk factors and the control group

\begin{tabular}{|c|c|c|c|c|c|c|c|c|}
\hline \multirow[t]{2}{*}{ Risk factor } & \multicolumn{2}{|c|}{$\begin{array}{l}\text { Neonates with a given risk } \\
\text { factor present }\end{array}$} & \multicolumn{2}{|c|}{$\begin{array}{c}\text { Neonates with other risk } \\
\text { factors }\end{array}$} & \multicolumn{2}{|c|}{ Control group } & \multirow[t]{2}{*}{$p^{I}$} & \multirow[t]{2}{*}{$p^{2}$} \\
\hline & $n$ & NGAL (ng/ml) & $n$ & NGAL (ng/ml) & $n$ & NGAL (ng/ml) & & \\
\hline \multicolumn{9}{|c|}{ Maternal disease / pregnancy-related pathology } \\
\hline Diabetes & 23 & $\begin{array}{c}75.24 \\
(25.57-302.97)\end{array}$ & 39 & $\begin{array}{c}126.47 \\
(17.47-536.57)\end{array}$ & 14 & $\begin{array}{c}64.34 \\
(30.36-42.04)\end{array}$ & NS & $<0.05$ \\
\hline Infection & 20 & $\begin{array}{c}143.38 \\
(25.57-536.57)\end{array}$ & 42 & $\begin{array}{c}114.02 \\
(17.47-519.80)\end{array}$ & & & NS & $<0.001$ \\
\hline $\begin{array}{l}\text { Genital tract } \\
\text { colonisation }\end{array}$ & 22 & $\begin{array}{c}132.92 \\
(27.82-519.80)\end{array}$ & 40 & $\begin{array}{c}117.69 \\
(17.47-536.57)\end{array}$ & & & NS & $<0.01$ \\
\hline Hypertension & 7 & $\begin{array}{c}90.99 \\
(58.89-209.61)\end{array}$ & 55 & $\begin{array}{c}126.47 \\
(17.47-536.57)\end{array}$ & & & NS & $<0.05$ \\
\hline Other & 5 & $\begin{array}{c}168.21 \\
(76.41-219.03)\end{array}$ & 57 & $\begin{array}{c}116.23 \\
(17.47-536.57)\end{array}$ & & & NS & $<0.005$ \\
\hline \multicolumn{9}{|l|}{ Perinatal pathology } \\
\hline PROM & 26 & $\begin{array}{c}110.12 \\
(17.47-536.57)\end{array}$ & 36 & $\begin{array}{c}139.53 \\
(27.82-519.80)\end{array}$ & & & NS & $<0.05$ \\
\hline Foetal distress & 26 & $\begin{array}{c}122.30 \\
(27.82-491.94)\end{array}$ & 36 & $\begin{array}{c}101.40 \\
(17.47-536.57)\end{array}$ & & & $<0.05$ & $<0.01$ \\
\hline \multicolumn{9}{|l|}{ Neonatal pathology } \\
\hline Early-onset infection & 10 & $\begin{array}{c}209.69 \\
(43.46-536.57)\end{array}$ & 52 & $\begin{array}{c}116.73 \\
(17.47-491.94)\end{array}$ & & & $<0.05$ & $<0.001$ \\
\hline $\begin{array}{l}\text { Congenital } \\
\text { malformation }\end{array}$ & 17 & $\begin{array}{c}126.47 \\
(17.47-282.52)\end{array}$ & 45 & $\begin{array}{c}116.23 \\
(25.57-536.57)\end{array}$ & & & NS & $<0.05$ \\
\hline Intrauterine hypoxia & 4 & $\begin{array}{c}197.17 \\
(17.47-491.94)\end{array}$ & 58 & $\begin{array}{c}117.69 \\
(25.57-536.57)\end{array}$ & & & - & - \\
\hline
\end{tabular}

PROM - premature rupture of membranes

$p^{I}-$ neonates with a given risk factor $v$ s. neonates with other risk factors

$p^{2}-$ neonates with a given risk factor vs. control group

size, neonates with intrauterine hypoxia were excluded from statistical analysis. Umbilical cord blood NGAL levels were significantly higher in neonates with infection and foetal distress compared to neonates with other perinatal risk factors $(p<0.05)$.

Similarly to umbilical cord blood, the highest peripheral blood NGAL levels were observed in neonates with infection and intrauterine hypoxia. In neonates with infection, peripheral blood NGAL level was significantly higher compared to neonates with other risk factors. Regardless of the analysed risk factor, we found no statistically significant differences in peripheral blood NGAL level compared to the control group.

Both umbilical cord and peripheral blood NGAL level did not increase with increasing number of perinatal risk factors present.

Evaluation of the effect of mode of delivery on NGAL levels in neonates showed significantly higher umbilical cord blood NGAL levels in neonates born by operative delivery compared to those born by natural delivery (Table 5).
Mode of delivery also had no effect on peripheral blood NGAL levels.

\section{Discussion}

Major advances that have occurred in the recent years in perinatology have not translated into improved ability to detect kidney injury in neonates. Due to limitations of the diagnosis of AKI based on serum creatinine level, increasing attention has been paid to new early AKI biomarkers that allow more rapid and specific identification of patients with kidney damage in older age groups.

In our study, umbilical cord blood NGAL levels in the control group $(64.37 ; 30.36-42.04 \mathrm{ng} / \mathrm{ml})$ were similar to peripheral blood NGAL levels at 1 DOL in healthy neonates reported by other authors [14, 24].

Due to an increasing spectrum of clinical conditions, in addition to kidney injury, in which elevated NGAL levels are seen in body fluids [25-27], in the present study we evaluated the effect of perinatal risk factors on umbilical 
Table 4. Comparison of peripheral blood NGAL levels in neonates with a specific risk factor vs. neonates with other risk factors and the control group

\begin{tabular}{|c|c|c|c|c|c|c|c|c|}
\hline \multirow[t]{2}{*}{ Risk factor } & \multicolumn{2}{|c|}{$\begin{array}{l}\text { Neonates with a given risk } \\
\text { factor present }\end{array}$} & \multicolumn{2}{|c|}{$\begin{array}{l}\text { Neonates with other risk } \\
\text { factors }\end{array}$} & \multicolumn{2}{|c|}{ Control group } & \multirow[t]{2}{*}{$p 1$} & \multirow[t]{2}{*}{$p 2$} \\
\hline & $n$ & NGAL (ng/ml) & $n$ & NGAL (ng/ml) & $n$ & NGAL (ng/ml) & & \\
\hline \multicolumn{9}{|c|}{ Maternal disease / pregnancy-related pathology } \\
\hline Diabetes & 23 & $\begin{array}{c}178.60 \\
(18.10-509.06)\end{array}$ & 39 & $\begin{array}{c}193.86 \\
(26.78-571.93)\end{array}$ & 14 & $\begin{array}{c}155.28 \\
(34.07-445.57)\end{array}$ & NS & NS \\
\hline Infection & 20 & $\begin{array}{c}153.39 \\
(53.48-542.81)\end{array}$ & 42 & $\begin{array}{c}210.78 \\
(18.10-571.93)\end{array}$ & & & NS & NS \\
\hline $\begin{array}{l}\text { Genital tract } \\
\text { colonisation }\end{array}$ & 22 & $\begin{array}{c}241.14 \\
(30.61-571.93)\end{array}$ & 40 & $\begin{array}{c}156.37 \\
(18.10-509.06)\end{array}$ & & & NS & NS \\
\hline Hypertension & 7 & $\begin{array}{c}103.27 \\
(38.86-277.45)\end{array}$ & 55 & $\begin{array}{c}193.86 \\
(18.10-571.93)\end{array}$ & & & NS & NS \\
\hline Other & 5 & $\begin{array}{c}83.65 \\
(49.78-336.28)\end{array}$ & 57 & $\begin{array}{c}193.86 \\
(18.10-571.93)\end{array}$ & & & NS & NS \\
\hline \multicolumn{9}{|c|}{ Perinatal pathology } \\
\hline PROM & 26 & $\begin{array}{c}237.97 \\
(18.10-507.83)\end{array}$ & 36 & $\begin{array}{c}156.37 \\
(30.61-571.93)\end{array}$ & & & NS & NS \\
\hline Foetal distress & 26 & $\begin{array}{c}175.81 \\
(30.61-542.81)\end{array}$ & 36 & $\begin{array}{c}179.11 \\
(18.10-571.93)\end{array}$ & & & NS & NS \\
\hline \multicolumn{9}{|l|}{ Neonatal pathology } \\
\hline $\begin{array}{l}\text { Early-onset } \\
\text { infection }\end{array}$ & 10 & $\begin{array}{c}457.35 \\
(76.87-571.93)\end{array}$ & 52 & $\begin{array}{c}156.37 \\
(18.10-509.06)\end{array}$ & & & $<0.05$ & NS \\
\hline Congenital defects & 17 & $\begin{array}{c}135.39 \\
(26.78-467.92)\end{array}$ & 45 & $\begin{array}{c}227.71 \\
(18.10-571.93)\end{array}$ & & & NS & NS \\
\hline $\begin{array}{l}\text { Intrauterine } \\
\text { hypoxia }\end{array}$ & 4 & $\begin{array}{c}269.61 \\
(26.78-507.83)\end{array}$ & 58 & $\begin{array}{c}179.11 \\
(18.10-571.93)\end{array}$ & & & --- & --- \\
\hline
\end{tabular}

PROM - premature rupture of membranes

$p^{I}-$ neonates with a given risk factor vs. neonates with other risk factors

$p^{2}-$ neonates with a given risk factor vs. control group

Table 5. Umbilical cord and peripheral blood NGAL levels (median, range) in neonates with perinatal risk factors in relation to the mode of delivery

\begin{tabular}{|c|c|c|c|}
\hline \multirow{2}{*}{$\begin{array}{l}\text { NGAL } \\
(\mathbf{n g} / \mathrm{ml})\end{array}$} & \multicolumn{2}{|c|}{ Mode of delivery } & \multirow[t]{2}{*}{$p$} \\
\hline & $\begin{array}{c}\text { Operative } \\
(n=37)\end{array}$ & $\begin{array}{l}\text { Natural } \\
(n=25)\end{array}$ & \\
\hline $\begin{array}{l}\text { Umbilical cord } \\
\text { blood }\end{array}$ & $\begin{array}{c}168.21 \\
(27.82-536.57)\end{array}$ & $\begin{array}{c}90.99 \\
(17.47-519.80)\end{array}$ & $<0.05$ \\
\hline $\begin{array}{l}\text { Peripheral } \\
\text { blood }\end{array}$ & $\begin{array}{c}178.60 \\
(30.61-571.93)\end{array}$ & $\begin{array}{c}179.61 \\
(18.10-509.06)\end{array}$ & NS \\
\hline
\end{tabular}

cord and peripheral blood NGAL level during the first five days of life.

We found a strong effect of infectious factors on NGAL levels in the study group, which may be explained by NGAL involvement in antibacterial defence mechanisms. Previous studies showed increased NGAL levels in body fluids, e.g. in urinary tract infections [28] and sepsis [29]. Tadesse et al. showed increased trophoblast NGAL expression in intrauterine infections [24]. In our study group, we found significantly higher NGAL levels in both umbilical cord blood and peripheral blood in neonates with infection. Similarly, albeit insignificantly, increased umbilical cord and peripheral blood NGAL levels were seen in neonates born by mothers with an infection during the last week of pregnancy. These findings indicate that inflammation is one of the factors that exert an effect on NGAL levels in body fluids independently of renal function, and this effect should be taken into account when NGAL level is used as a biomarker of AKI. The finding of higher umbilical cord blood NGAL levels indicates that it may be a potential early marker of neonatal inflammation.

Another evaluated factor that is of importance for increased NGAL expression is hypoxia, considered a major cause of AKI in neonates. Although identification of intrauterine hypoxia in only four neonates precluded statistical 
analysis, both umbilical cord and peripheral blood NGAL levels in these neonates were higher compared to neonates born in a general good condition. In our study group, significantly higher umbilical cord blood NGAL levels were seen in neonates with foetal distress. These results are in accordance with observations of other authors who showed elevated NGAL levels in neonates with asphyxia, both with AKI and with normal renal function, measured in umbilical cord blood [22] and peripheral blood [9, 13, 14].

Although increased umbilical cord blood NGAL levels compared to the control group were seen in neonates at risk due to maternal disease such as diabetes, infection, or hypertension, perinatal pathology such as PROM, or congenital defects, the differences were not significant in comparison to other perinatal risk factors.

It is unclear why significantly higher umbilical cord blood NGAL levels were found in 37 neonates $(60 \%)$ born by operative delivery compared to those born by normal delivery. Although it might have been related to higher rates of risk factors in this group, significantly higher umbilical cord blood NGAL levels were also seen in the control group where the decision to perform a caesarean section was due to maternal indications (e.g. maternal visual impairment or previous caesarean section). Understanding of the effect of mode of delivery on NGAL levels requires further studies. No effect of mode of delivery on peripheral blood NGAL level may suggest that its source was the placenta and not kidneys of the neonate.

Our findings indicate that neonatal infection and intrauterine hypoxia or mode of delivery may affect NGAL levels in neonatal body fluids during the first days of life, a fact that should be taken into account when interpreting NGAL level measurement results. Definite determination of the effect of specific perinatal risk factors on neonatal NGAL levels would require a larger study, allowing multivariate analysis or identification of a larger number of neonates with isolated specific risk factors.

\section{Conclusions}

1. Neonatal NGAL levels are affected by infection and intrauterine hypoxia.

2. NGAL level in umbilical cord blood may be an early noninvasive marker of neonatal infection.

The authors declare no conflict of interest.

\section{References}

1. Selewski DT, Charlton JR, Jetton JG, et al. (2005): Neonatal Acute Kidney Injury. Pediatrics 136: e463-e473.

2. Andreoli SP. (2004): Acute renal failure in the newborn. Semin Perinatol 28: 112-123.

3. Cataldi L, Leone R, Moretti U, et al. (2005) Potential risk factors for the development of acute renal failure in preterm newborn infants: a case-control study. Arch Dis Child Fetal Neonatal Ed 90: F514-F519.

4. Iacobelli S, Bonsante F, Ferdinus C, et al. (2009): Factors affecting postnatal changes in serum creatinine in preterm infants with gestational age $<32$ weeks. J Perinatol 29: 232236.

5. Cuzzolin L, Fanos V, Pinna B, et al. (2006): Postnatal renal function in preterm newborns: a role of diseases, drugs and therapeutic interventions. Pediatr Nephrol 21: 931-938.

6. Karlowicz MG, Adelman RD (1995): Nonoliguric and oliguric acute renal failure in asphyxiated term neonates. Pediatr Nephrol 9: 718-722.

7. Guignard JP, Drukker A (1999): Why do newborn infants have a high plasma creatinine? Pediatrics 103: e49.

8. Askenazi DJ, Ambalavanan N, Goldstein SL (2009): Acute kidney injury in critically ill newborns: what do we know? What do we need to learn? Pediatr Nephrol 24: 265-274.

9. Sarafidis K, Tsepkentzi E, Agakidou E, et al. (2012): Serum and urine acute kidney injury biomarkers in asphyxiated neonates. Pediatr Nephrol 27: 1575-1582.

10. Askenazi DJ, Montesanti A, Hunley H, et al. (2011): Urine biomarkers predict acute kidney injury and mortality in very low birth weight infants. J Pediatr 159: 907-912.

11. Askenazi DJ, Koralkar R, Hundley HE, et al. (2012): Urine biomarkers predict acute kidney injury in newborns. J Pediatr 161: $270-275$

12. Singer E, Elger A, Elitok S, et al. (2011): Urinary neutrophil gelatinase-associated lipocalin distinguishes pre-renal from intrinsic renal failure and predicts outcomes. Kidney Int 80: 405-414.

13. Pejovic B, Eric-Marinkovic J, Pejovic M, et al. (2015): Detection of acute kidney injury in premature asphyxiated neonates by serum neutrophil gelatinase-associated lipocalin ( $\mathrm{sN}$ GAL)-sensitivity and specificity of a potential new biomarker. Biochem Med (Zagreb) 25: 450-459.

14. Raggal NE, Khafagy SM, Mahmoud NH, et al. (2013): Serum neutrophil gelatinase-associated lipocalin as a marker of acute kidney injury in asphyxiated neonates. Indian Pediatr 50: 459-462.

15. Parravicini E, Nemerofsky SL, Michelson KA, et al. (2010): Urinary neutrophil gelatinase-associated lipocalin is a promising biomarker for late onset culture-positive sepsis in very low birth weight infants. Pediatr Res 67: 636-640.

16. Inoue H, Ohga S, Kusuda T, et al. (2013): Serum neutrophil gelatinase-associated lipocalin as a predictor of the development of bronchopulmonary dysplasia in preterm infants. Early Hum Dev 89: 425-429.

17. Krawczeski CD, Woo JG, Wang Y, et al. (2011): Neutrophil gelatinase-associated lipocalin concentrations predict development of acute kidney injury in neonates and children after cardiopulmonary bypass. J Pediatr 158: 1009-1015.

18. Essajee F, Were F, Admani B (2015): Urine neutrophil gelatinase-associated lipocalin in asphyxiated neonates: a prospective cohort study. Pediatr Nephrol 30: 1189-1196.

19. Lavery AP, Meinzen-Derr JK, Anderson E, et al. (2008): Urinary NGAL in premature infants. Pediatr Res 64: 423-428.

20. Huynh TK, Bateman DA, Parravicini E, et al. (2009): Reference values of urinary neutrophil gelatinase-associated lipocalin in very low birth weight infants. Pediatr Res 66: 528-532.

21. Saeidi B, Koralkar R, Griffin RL, et al. (2015): Impact of gestational age, sex, and postnatal age on urine biomarkers in premature neonates. Pediatr Nephrol 30: 2037-2044. 
22. Surmiak P, Baumert M, Fiala M, et al. (2014): Umbilical cord blood NGAL concentration as an early marker of perinatal asphyxia in neonates. Ginekol Pol 85: 424-427.

23. Chen C-N, Chou C-H, Jeng S-F, et al. (2016): Urinary Neutrophil Gelatinase-Associated Lipocalin Levels in Neonates. Pediatr Neonatol 57: 207-212.

24. Tadesse S, Luo G, Park JS, et al. (2011): Intra-amniotic infection upregulates neutrophil gelatinase-associated lipocalin (NGAL) expression at the maternal-fetal interface at term: implications for infection-related preterm birth. Reprod Sci 18: 713-722.

25. Medic B, Rovcanin B, Vujovic KS, et al. (2016): Evaluation of novel biomarkers of acute kidney injury: the possibilities and limitations. Curr Med Chem 23(: 1981-1997.

26. Suchojad A, Tarko A, Smertka M, et al. (2015): Factors limiting usefulness of serum and urinary NGAL as a marker of acute kidney injury in preterm newborns. Ren Fail 37: 439445.

27. Al-Ismaili Z, Palijan A, Zappitelli M (2011): Biomarkers of acute kidney injury in children: discovery, evaluation, and clinical application. Pediatr Nephrol 26: 29-40.

28. Sim JH, Yim HE, Choi BM, et al. (2015): Plasma neutrophil gelatinase-associated lipocalin predicts acute pyelonephritis in children with urinary tract infections. Pediatr Res 78: 48-55.

29. Otto GP, Hurtado-Oliveros J, Chung H-Y, et al. (2015): Plasma Neutrophil Gelatinase-Associated Lipocalin Is Primarily Related to Inflammation during Sepsis: A Translational Approach. PLoS One 10: e0124429. 